\title{
CORRIGENDUM
}

\section{Confronting the Epidemic: The Need for Global Solutions}

NJ RIGBY, S KUMANYIKA and WP JAMES Journal of Public Health Policy (2006) 27, 2 I 5. doi:I0.1057/palgrave.jphp.3200080

Correction to: Journal of Public Health Policy, 2004, 25(3-4): 4I $8-434$.

The above paper was supplied to JPHP without an abstract and one was therefore written by the Editors. The authors have subsequently requested that this be replaced by the following new text:

\section{A B S T R A C T}

The growth in the global epidemic of obesity is fundamentally linked to economic factors. The rising prevalence of overweight and obesity has occurred during a period when the real cost of the main components of many processed foods has declined significantly, partly due to state subsidies in the protected markets of Western economies. It is suggested that the vigorous promotion of foods high in fats and sugars, and intensive marketing to children, have aggravated the problems of obesity. The metabolic syndrome, a recent feature of the epidemic, now is a marker for the health impact of obesity both in the US and other countries. The IOTF suggests that global populations will continue to become progressively heavier if present consumption forecasts are sustained, with obesity imposing a burden of social and economic costs that no country, least of all developing countries with limited resources, can afford. Commitments to deliver effective action are needed from non-health sectors such as culture and education, commerce and trade, development, planning, and transport. Only a comprehensive and integrated international approach, based on an effective implementation of the WHO global strategy on diet, physical activity and health, offers any real hope of arresting the public health catastrophe unfolding throughout the world. 